\title{
Multilayer End Coupled Band Pass Filter using Low-temperature Co-fired Ceramic Technology for Broadband Fixed Wireless
}

\author{
Zulkifli Ambak, Hizamel M.Hizan², Ahmad Ismat Abdul Rahim³, Azmi Ibrahim, \\ Mohd Zulfadli M. Yusoff ${ }^{5}$, Razali Ngah ${ }^{6}$ \\ ${ }^{1,2,3,4,5}$ Communication Technology, TM Research \& Development Sdn Bhd, Lingkaran Teknokrat, \\ 63000, Cyberjaya, Selangor, Malaysia \\ ${ }^{6}$ Wireless Communication Center, Faculty of Electrical Engineering, Universiti Teknologi Malaysia, \\ 81310, Johor, Malaysia
}

\section{Article Info}

Article history:

Received Jan 5, 2018

Revised Mar 2, 2018

Accepted Mar 18, 2018

Keywords:

Broadband fixed wireless

End coupled BPF

LTCC

\begin{abstract}
This paper presents design approach for realizing multilayer End Coupled Bandpass Filter (ECBPF) using low temperature co-fired ceramic (LTCC) technology at TMRND's LTCC Lab. Design method for the ECBPF is based on the coupled-resonator filter which was realized in LTCC multilayer substrate and operating at the center frequency of $42 \mathrm{GHz}$. Three samples of EC BPF have been designed, simulated, fabricated and investigated in terms of performance and structure size. This multilayer ECBPF were fabricated in the 8 layers LTCC Ferro A6S materials with dielectric constant of 5.8, loss tangent of 0.002 and metallization of gold. The measured insertion loss for ECBPF was $2.43 \mathrm{~dB}$ and return loss was $22.81 \mathrm{~dB}$ at the center frequency at $42 \mathrm{GHz}$. The overall size of the fabricated filter was $6.0 \mathrm{~mm} \times 2.5 \mathrm{~mm} \times$ $0.77 \mathrm{~mm}$.
\end{abstract}

Copyright (C) 2018 Institute of Advanced Engineering and Science. All rights reserved.

Corresponding Author:

Zulkifli Ambak, Communication Technologies, TM Research and Development Sdn Bhd, Lingkaran Teknokrat Timur, 63000, Cyberjaya, Selangor, Malaysia.

Email: zulkifliambak@tmrnd.com.my

\section{INTRODUCTION}

The rapid development in microwave and millimeter wave communication technology is demand for high quality, miniaturization, and low-cost fabrication of passive components such as the microstrip bandpass filters (BPF) and antennas. The next generation of wireless communication networks envisages operation at millimeter-wave frequencies $(>30 \mathrm{GHz})$ to achieve the high data speed where larger allocable bandwidth is available for gigabit/s transmissions.Several applications were developed in microwave and millimeter wave (mm-wave) band to achieve the high-speed data transmission including for mm-wave Radio over Fiber (RoF) application as reported in [1-3]. In general, the bandpass filter is one of an important passive component in microwave and millimeter wave communication system because of its function for permitting signal in the desired range of frequencies and rejecting all other. There are many filter topologies at microwave and mm-wave frequencies as reported such as the parallel-coupled-resonator filters [4] and the hairpin resonator filters [5] which have a problem with a large size, the high loss due to the increased resonator capacitance, low stopband rejection, and spurious response at the filter's harmonics. We need to use different feed topologies and multilayer structure to reduce the size and improve insertion loss such as parallel-coupled-feed structure [6], tapped-line [7], and the end-coupled structures [8]. 
One of the important packaging technologies to integrate passives elements such as filters and antenna is the Low-Temperature Co-fired Ceramic (LTCC) technology. This LTCC technology allows for the realization of compact devices which makes use of ceramic tapes with low loss material systems such as Ferro A6S material which has a dielectric constant of 5.8 and loss tangents of 0.002 [9]. The main drawback implementation of the planar bandpass filter at higher microwave and millimeter wave frequencies are the dimensional limitations in fabrication technologies such as printed circuit board (PCB) and Low-Temperature Co-Fired Ceramic (LTCC) technology. For example, conventional planar end-coupled BPF is impossible to be implemented because of the tight coupling between the resonator, the band gap is narrow and the LTCC print screen process with the minimum gap between line resolution is less than 100um[10]. In this paper, we proposed design from planar to multilayer end coupled bandpass filter (ECBPF) to overcome the problem of the dimensional limitation of fabrication technologies. The multilayer ECBPF structure with vertically stacked 2 stage resonators, 6 grounded layers, a fractional bandwidth of $7.14 \%$ and size reduction of $30 \%$ compared with an equivalent LTCC end coupled microstrip filter [10] was designed and developed at a center frequency of $42 \mathrm{GHz}$ using LTCC technology. The fabricated multilayer ECBPF size was $6.0 \mathrm{~mm} \mathrm{x}$ $2.5 \mathrm{~mm} \times 0.77 \mathrm{~mm}$.

\section{DESIGN OF THE MULTILAYER END COUPLED BANDPASS FILTER}

In this paper, the basic structure of the Multilayer ECBPF is based on the coupled-resonator filter which was realized in LTCC multilayer substrate and operating at the center frequency of $42 \mathrm{GHz}$. This multilayer ECBPF is important parts of the Remote Antenna Unit (RAU) Transmitter for mm-wave RoF applications. Figure 1 shows the proposed block diagram of RAU Transmitter for Radio over Fiber system where operating at Broadband Fixed Wireless Access frequency of $40 \mathrm{GHz}$. The photodetector (PD) converts optical input signal within 1100-1650nm wavelength to the radio frequency signal within the range of 3743.5GHz. The radio frequency signal is amplified by the Low Noise Amplifier (LNA) module and then passed through the band pass filter. The filtered signal is then amplified again to the desired power level by the Power Amplifier (PA) module before being transmitted to the antenna. In this work, multilayer ECBPF was designed fabricated and measured. The design methodology for implementing the structure of the multilayer ECBPF begins from finalizing the specification, design the schematic circuit by computer-aided techniques and then generate the physical layout realization through electromagnetic (EM) simulation tools. The general design procedure to design and develop the multilayer ECBPF can be summarized as:

a. define and finalize the specification

b. derive a schematic circuit

c. circuit optimization

d. generate a physical layout based on the circuit

e. tune the layout to meet required specifications

f. fabricate LTCC prototypes

g. testing to verify the performance

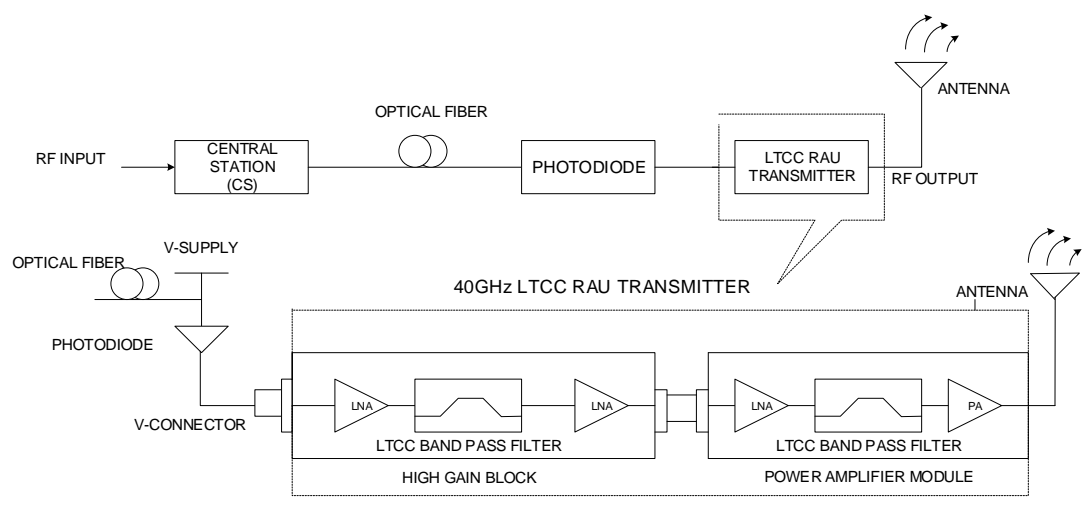

Figure 1. Block diagram of the $40 \mathrm{GHz}$ RAU transmitter for RoF system

The design specification for multilayer ECBPF using LTCC technology is shown in Table 1. It was designed using 8 layers LTCC Ferro A6S tapes systems with relative dielectric constant and a loss tangent of 5.8 and 0.002 respectively. The thickness of single layers was $96 \mu \mathrm{m}$. It consists of the two layers were 
required for end coupled resonator BPF and 6 layers used as Grounded planes as illustrated in Figure 2(a). Figure 2(b) shows the 3D view design layout which generated through CST electromagnetic (EM) simulation tools. The total dimension of proposed bandpass filter was $6.0 \mathrm{~mm} \times 2.5 \mathrm{~mm} \times 0.77 \mathrm{~mm}$.

Table 1. Design specification

\begin{tabular}{clcc}
\hline No & \multicolumn{3}{c}{ LTCC MULTILAYER ECBPF } \\
\hline & \multicolumn{1}{c}{ Items } & Targeted & Unit \\
1 & Frequency range & $40.5-43.5$ & $\mathrm{GHz}$ \\
2 & Center Frequency & 42 & $\mathrm{GHz}$ \\
3 & Passband width & 3 & $\mathrm{GHz}$ \\
4 & Insertion Loss (S21) & $<3$ & $\mathrm{~dB}$ \\
5 & Return Loss (S11) & $>10$ & $\mathrm{~dB}$ \\
6 & Impedance & 50 & $\Omega$ \\
\hline
\end{tabular}

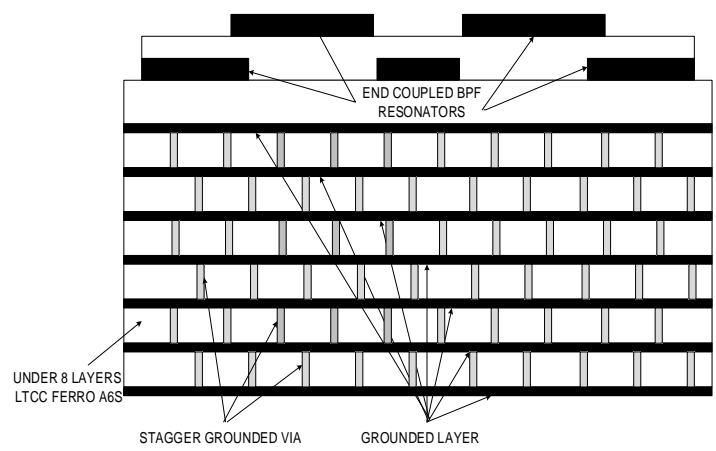

(a)

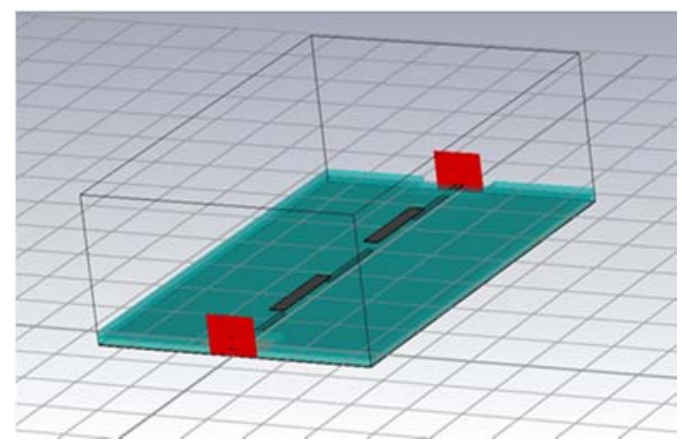

(b)

Figure 2. The configuration of the LTCC Multilayer ECBPF a) Cross section, and b) 3D view using CST EM Software

Three samples of multilayer ECBPF as marking as sample A, B and C (see Figure 7) were designed, fabricated, measured and analyzed in order to check the filter performances in term of insertion loss and structure size. The performances of the 3 samples of the multilayer ECBPF with Ground Signal Ground (GSG) ports were investigated. Expected result for the end coupled BPF at the center frequency of $42 \mathrm{GHz}$ with insertion loss, $\mathrm{S} 21$ less than $3 \mathrm{~dB}$ and return loss more than $10 \mathrm{~dB}$.

In theory, according to J.Hong and M.J Lancaster [11], the general configuration of an end coupled microstrip bandpass filter is illustrated in Figure 3 where each open end microstrip resonator is approximately a half guided wavelength long at the center frequency $\mathrm{f}_{\mathrm{o}}$ of the bandpass filter. The coupling from one resonator to the other is through the gap between the two adjacent open ends and hence is capacitive. The gap can be represented by the inverters, which are of the form in Figure 4 . These J-inverters tend to reflect high impedance levels to the ends of each of the half wavelength resonators and it can be shown that this causes the resonators to exhibit a shunt type resonance.

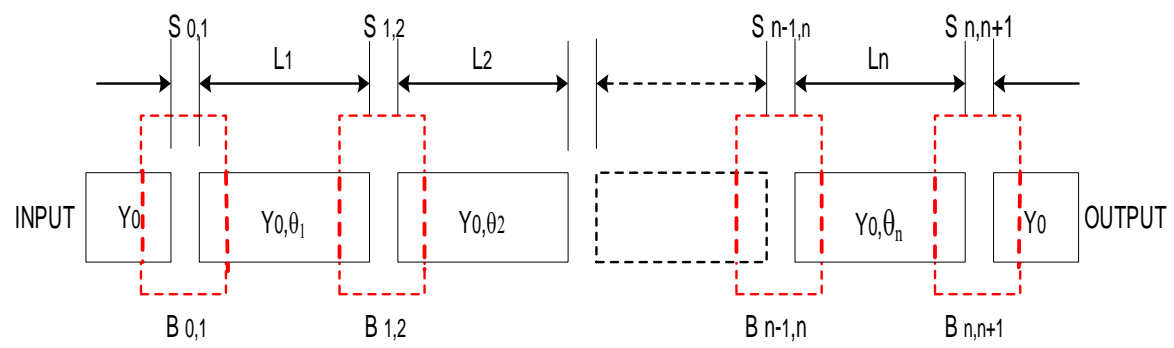

Figure 3. General configuration of end coupled microstrip bandpass filter 


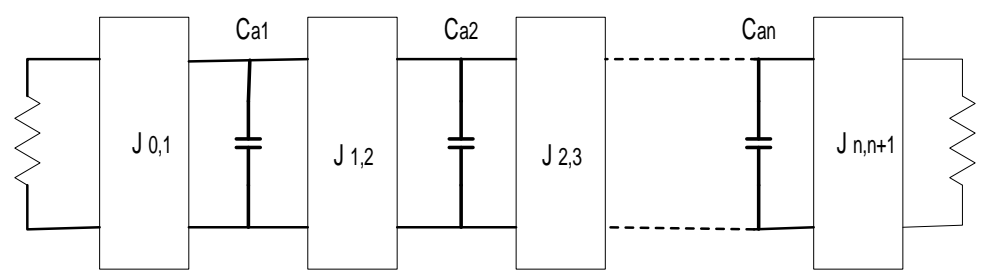

Figure 4. Lowpass prototype filters equivalent model with J-inverter

The general Equations for end coupled BPF design parameters are given as follows:

$$
\begin{aligned}
& \frac{J 0,1}{Y 0}=\sqrt{\frac{\pi F B W}{2 g 0 g 1}} \\
& \frac{J j, j+1}{Y 0}=\frac{\pi F B W}{2} \frac{1}{\sqrt{g j g j+1}} \quad ; \mathrm{J}=1 \text { to } \mathrm{n}-1 \\
& \frac{J n, n+1}{Y 0}=\sqrt{\frac{\pi F B W}{2 g n g n+1}}
\end{aligned}
$$

Where by

$\mathrm{Jj}, \mathrm{j}+1$ : Characteristic admittances of J-inverters

Yo: Characteristic admittances of the MSL

g $0, \mathrm{~g} 1 \ldots, \mathrm{g}$ n: Element of a ladder type low pass prototype with a normalized cutoff frequency

FBW: a fractional bandwidth of the band pass filter $=(\mathrm{f}$ high $-\mathrm{f}$ low $/ \mathrm{f}$ center $)$

The value of characteristic impedance, J-inverter can be obtained with equation (1) to (3) if the type order and ripple (in Chebyscheff type) of the mm-wave bandpass filter are determined. For the wideband filter, we need tight coupling between the resonator and the band gap must be very narrow. From the calculation, the filter has FBW of 7.14\%, hence this filter can be categorized as a narrowband filter because of fractional bandwidth (FBW) less than 20\%. BPFs can be classified as a narrow bandpass filter and wide bandpass filter on the basis of their FBW. With the FBW of $20 \%$ or less is classified as narrow bandpass filter whereas the wideband pass filters are those who are FBW much higher than the $20 \%$. A good bandpass filter requires low passband insertion loss and large suppression in the rejection area including the image signal and in-band signal harmonics. When the frequency is low, e.g., for most wireless communication applications, filters are usually implemented by LC element type. In our LTCC design rules, the resolution of print screen process, the minimum gap between lines is 100um. Assuming the capacitive gaps act as perfect, series capacitance discontinuities of susceptance $\mathrm{B} \mathrm{j}, \mathrm{j}+1$ as shown in Figure 5.

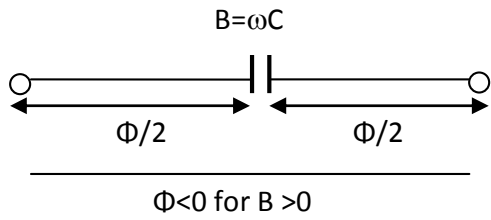

Figure 5. Immittance inverters comprised of lumped and transmission line elements

Design parameters Equation as follows:

Susceptance

$$
\frac{B, j+1}{Y o}=\frac{\frac{J_{j, j+1}}{Y o}}{1-\left(\frac{J j, j+1}{Y o}\right)^{2}}
$$

Electrical length of the J-inverters associates with jth half wavelength Resonator

$$
\theta j=\pi-\frac{1}{2}\left[\tan ^{-1} \frac{2 B j-1, j}{Y 0}+\tan ^{-1} \frac{2 B j, j+1}{Y 0}\right] \text { radians }
$$


Where the $\mathrm{Bj}, \mathrm{j}+1$, and $\theta j$ are evaluated at fo

Coupling gaps, $\mathrm{Sj}, \mathrm{j}+1$ of the microstrip end coupled resonator filter can be determined as obtained the series capacitances that satisfy:

$$
\operatorname{Cg}^{\mathrm{j}, \mathrm{j}+1}=\frac{\mathrm{B}_{\mathrm{j}, \mathrm{j}+1}}{\omega_{0}}
$$

Whereby $\omega_{0}=2 \pi \mathrm{f}_{0}$ is the angular frequency of the mid-band.

The physical lengths of resonators are given by

$$
\mathrm{l}_{\mathrm{j}}=\frac{\lambda_{\mathrm{g} 0}}{2 \pi} \theta_{\mathrm{j}}-\Delta \mathrm{lj}^{\mathrm{e} 1}-\Delta \mathrm{lj}^{\mathrm{e} 2}
$$

Effective length

$$
\begin{aligned}
& \Delta \mathrm{lj}^{\mathrm{e} 1}=\frac{\omega_{0} \mathrm{Cp}^{\mathrm{j}-1, \mathrm{j}}}{\mathrm{Yo}} \frac{\lambda_{\mathrm{g} 0}}{2 \pi} \\
& \Delta \mathrm{lj}^{\mathrm{e} 2}=\frac{\omega_{0} \mathrm{Cp}^{\mathrm{j}, \mathrm{j}+1}}{Y_{0}} \frac{\lambda_{\mathrm{g} 0}}{2 \pi}
\end{aligned}
$$

From the above mathematical equations, design parameter of the band gap and physical length for multilayer ECBPF can be obtained as shown in Table 2. Figure 6(a) and (b) show the top view and cross-section of the band gap, physical length and vertical coupling of the proposed filter.

Table 2. Design parameters for LTCC Multilayer ECBPF

\begin{tabular}{cccc}
\hline No & Items & Design & Remarks \\
\hline 1 & S0,1 & $210 \mathrm{um}$ & Overlap \\
2 & S1,2 & $30 \mathrm{um}$ & Spacing \\
3 & S2,3 & $30 \mathrm{um}$ & Spacing \\
4 & S3,4 & $210 \mathrm{um}$ & Overlap \\
5 & L0 & $1000 \mathrm{um}$ & \\
6 & L1 & $1410 \mathrm{um}$ & \\
7 & L2 & $1343 \mathrm{um}$ & \\
\hline
\end{tabular}
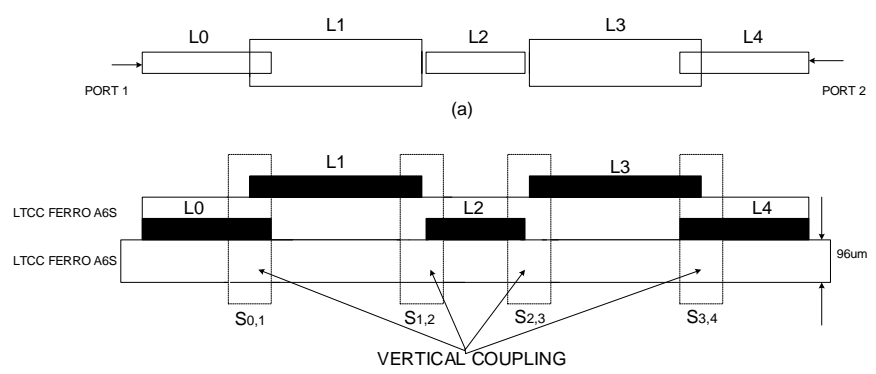

(b)

Figure 6. Design of the multilayer ECBPF (a) Top view, and (b) Cross section at 2 layers

\section{LTCC FABRICATION AND MEASUREMENT OF MULTILAYER END COUPLED BANDPASS FILER}

The multilayer ECBPF was fabricated using state-of-the-art in-house TMRND's LTCC process was described in [12]. Figure 7 shows fabricated multilayer end coupled BPF with 3 samples mark as sample A, B, and C.The detail physical dimensions of the LTCC BPF are listed in Table 3. All the designs complied with in-house TMRND's LTCC design guidelines with minimum spacing at $100 \mu \mathrm{m}$ between lines. 


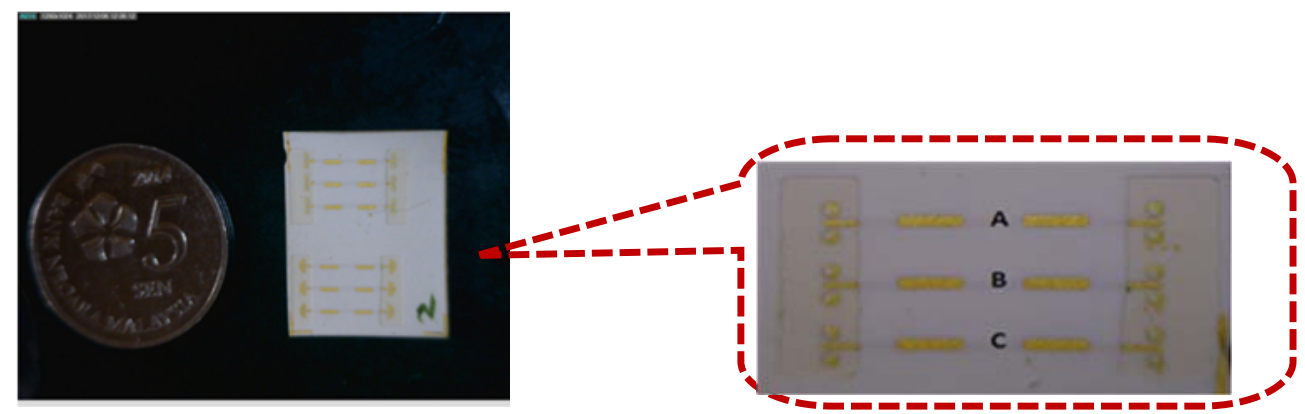

Figure 7. Fabricated LTCC multilayer ECBPF with conductor Gold

\begin{tabular}{|c|c|c|c|c|c|}
\hline \multirow{3}{*}{ Item } & \multicolumn{5}{|c|}{ DESIGN AND FABRICATED LTCC BPF DIMENSION } \\
\hline & \multirow{2}{*}{$\begin{array}{l}\text { Designed } \\
\text { (in } \mu \mathrm{m} \text { ) }\end{array}$} & \multicolumn{3}{|c|}{ Fabricated (in $\mu \mathrm{m}$ ) } & \multirow[t]{2}{*}{ Remarks } \\
\hline & & A & B & $\mathrm{C}$ & \\
\hline S 0,1 & 210 & 160 & 200 & 200 & Overlap \\
\hline $\mathrm{S} 1,2$ & 30 & 30 & 25 & 30 & Spacing \\
\hline S 2,3 & 30 & 30 & 25 & 30 & Spacing \\
\hline S 3,4 & 210 & 160 & 200 & 200 & Overlap \\
\hline L0 & 1000 & 1000 & 1000 & 1000 & \\
\hline L1 & 1410 & 1446 & 1418 & 1486 & \\
\hline L2 & 1343 & 1333 & 1359 & 1370 & \\
\hline L3 & 1410 & 1446 & 1418 & 1486 & \\
\hline
\end{tabular}

Figure 8(a), (b) and (c) show the measurement results compared with simulation results for the Multilayer ECBPF is based on the coupled-resonator filter which was realized in LTCC multilayer substrate and operating at the center frequency of $42 \mathrm{GHz}$. The simulated results presented in Figure 9 shows the multilayer ECBPF has centered at $42 \mathrm{GHz}$ with insertion loss of $2.28 \mathrm{~dB}$ and return loss of $11.66 \mathrm{~dB}$. The simulated and measured responses of the design were summarized in Table 4 for three (3) samples A, B, and C. All the measurements were done by using the R\&S ZVA50 network analyzer and Cascade Microtech $450 \mu \mathrm{m}$ probe tips. From the results, we found that the sample $\mathrm{C}$ gave the best result compared to others, with the insertion loss and return loss of $2.43 \mathrm{~dB}$ and $22.81 \mathrm{~dB}$, respectively. However, the measured insertion loss at center frequency was $0.15 \mathrm{~dB}$ larger than simulated results. A different might due to shrinkages of the conductor layer which results in an increase of spacing and gap of each filter section. Additionally, the increased insertion loss might be caused roughness of the fired circuits. Furthermore, the measured result has good agreement compared to simulated result.

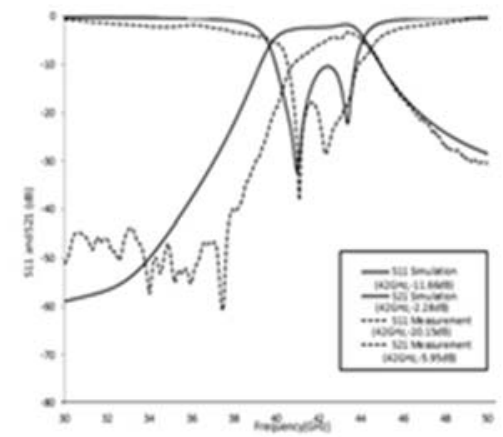

(a)

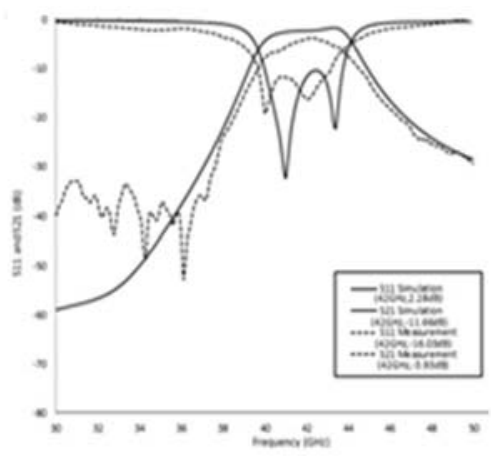

(b)

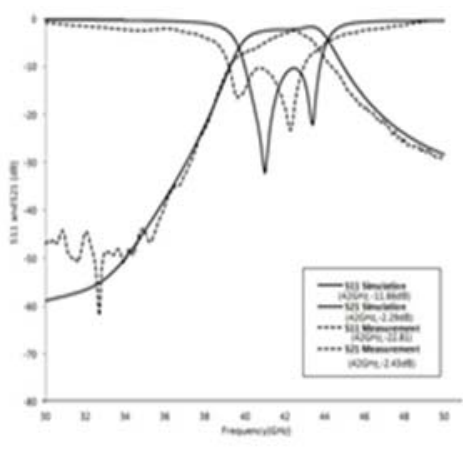

(c)

Figure 8. Simulated and measured results for LTCC ECBPF a) Sample A b) Sample B, and c) Sample C 
Table 4. Simulated and measured results for the multilayer EC BPF

\begin{tabular}{|c|c|c|c|c|c|c|c|c|c|}
\hline \multirow{3}{*}{ Parameter } & \multicolumn{6}{|c|}{ SIMULATED AND MEASURED RESULTS } & \multicolumn{3}{|c|}{ References } \\
\hline & \multirow[t]{2}{*}{ Spec } & \multirow[t]{2}{*}{ Simulated } & \multicolumn{3}{|c|}{ Measured } & \multirow[t]{2}{*}{ Unit } & \multirow[t]{2}{*}[8]{} & \multirow[t]{2}{*}[10]{} & \multirow[t]{2}{*}{ Unit } \\
\hline & & & A & $\mathrm{B}$ & $\mathrm{C}$ & & & & \\
\hline $\begin{array}{c}\text { Center } \\
\text { Frequency }\end{array}$ & 42 & 42 & 42 & 42 & 42 & $\mathrm{GHz}$ & 34.6 & 44.2 & $\mathrm{GHz}$ \\
\hline $\begin{array}{c}\text { Pass } \\
\text { bandwidth }\end{array}$ & 3 & 4.5 & 3.5 & 4.3 & 3.5 & & 3 & 2 & \\
\hline $\begin{array}{c}\text { Insertion Loss } \\
(\mathrm{S} 21)\end{array}$ & $<3$ & 2.28 & 5.95 & 3.93 & 2.43 & $\mathrm{~dB}$ & 2.96 & $<3.6$ & $\mathrm{~dB}$ \\
\hline $\begin{array}{l}\text { Return Loss } \\
\text { (S11) }\end{array}$ & $>10$ & 11.66 & 20.15 & 16.03 & 22.81 & $\mathrm{~dB}$ & 19 & $>18$ & $\mathrm{~dB}$ \\
\hline Topology & & & $\begin{array}{c}\text { End } \\
\text { Coupled }\end{array}$ & $\begin{array}{c}\text { End } \\
\text { Coupled }\end{array}$ & $\begin{array}{c}\text { End } \\
\text { Coupled }\end{array}$ & & $\begin{array}{c}\text { End } \\
\text { Coupled }\end{array}$ & End Coupled & \\
\hline $\begin{array}{l}\text { LTCC } \\
\text { Substrate }\end{array}$ & & & Ferro A6S & Ferro A6S & Ferro A6S & & $\begin{array}{l}\text { Ferro } \\
\text { A6M }\end{array}$ & $\begin{array}{c}\text { Dupont } \\
943\end{array}$ & \\
\hline $\begin{array}{l}\text { Dielectric } \\
\text { constant, \&r }\end{array}$ & & & 5.8 & 5.8 & 5.8 & & 5.9 & 7.4 & \\
\hline $\begin{array}{l}\text { Size } \\
\text { Dimension } \\
\text { (after fired) }\end{array}$ & & & $\begin{array}{l}\mathrm{L}: 5.82 \mathrm{~mm} \\
\mathrm{~W}: 2.5 \mathrm{~mm} \\
\mathrm{H}: 0.77 \mathrm{~mm}\end{array}$ & $\begin{array}{c}\mathrm{L}: 5.85 \mathrm{~mm} \\
\mathrm{~W}: 2.5 \mathrm{~mm} \\
\mathrm{H}: 0.77 \mathrm{~mm}\end{array}$ & $\begin{array}{c}\mathrm{L}: 6.0 \mathrm{~mm} \\
\mathrm{~W}: 2.5 \mathrm{~mm} \\
\mathrm{H}: 0.77 \mathrm{~mm}\end{array}$ & $\mathrm{~mm}$ & $\begin{array}{c}\mathrm{L}: 11.7 \mathrm{~mm} \\
\mathrm{~W}: 6.6 \mathrm{~mm} \\
\mathrm{H}: 1.60 \mathrm{~mm}\end{array}$ & $\begin{array}{c}\mathrm{L}: 8.0 \mathrm{~mm} \\
\mathrm{~W}: 3.0 \mathrm{~mm} \\
\mathrm{H}: 0.55 \mathrm{~mm}\end{array}$ & \\
\hline
\end{tabular}

\section{CONCLUSION}

This paper proposed the multilayer ECBPF with vertically stacked 2 stage resonators and 6 grounded layers, a fractional bandwidth of $7.14 \%$ and size reduction of $30 \%$ comparing with an equivalent LTCC end coupled microstrip filter. The advantage of the proposed structure is to overcome the problem with the planar structure of end coupled BPF due to dimensional limitations in fabrication technologies. From the results, we found that sample $\mathrm{C}$ gave the best result compared to others, with the insertion loss and return loss of $2.43 \mathrm{~dB}$ and $22.81 \mathrm{~dB}$, respectively at the center frequency of $42 \mathrm{GHz}$ which good agreement with simulated results. As summarized, the variations between the measured and designed dimensions were defined and measured relative to the guided wavelength at the design center frequency. Therefore, we need to optimize the design in the next stage for further improvement.

\section{REFERENCES}

[1] Luca pergola.,"LTCC based RF Frontends for WLAN Applications and Radio over Fiber Systems," P.H.D thesis, ETH Zurich,2007

[2] H. B. Kim, et al, “A Radio over Fiber based Wireless Access Network Architecture for Rural Areas.” Proceeding 14th IST Mobile and Wireless Communication Summit, Dresden, Germany, June 2005.

[3] Syamsuri Yaakob, et al.," 40-GHz ROF downlink system with SFP modules,” Microw. Opt. Technol. Lett.,56: pp:900-903.

[4] Aly H. Aly, et al., "Modeling and Measurements of Novel Monolithic Filters, "Active and Passive Electronic Components, vol. 2008, Article ID 537069, 8 pages, 2008.

[5] S. B. Cohn, "Parallel-coupled transmission-line-resonator filters," IRE Transactions onMicrowave Theory and Techniques, vol. 6, no. 2, pp. 223-231, 1998.

[6] E. G. Cristal and S. Frankel, "Hairpin-line and hybrid hairpin-line/half-wave parallel-coupled-line filters," IEEE Transactions on Microwave Theory and Techniques, vol. 20, no. 11, pp. 719-728, 1972.

[7] J. S. Wong, "Microstrip tapped-line filter design," IEEE Transactions on Microwave Theory and Techniques, vol. 27, no. 1 , pp. 44-50,1979.

[8] Xu Ziqiang, et al., "34GHz Bandpass filter for Low-Temperature Co-fired Ceramic System in Package Application", Chinese Journal of Mechanical Engineering, Vol XX, No X, 2011.

[9] Z. Ambak, et al., "Design of 40GHz multilayer end coupled bandpass filter using LTCC technology," IEEE International Conference on Semiconductor Electronics (ICSE2014),pp.294-297,2014

[10] Min-Soo Kang, et al., "End Coupled Stripline BPF Using LTCC in Millimeter-Wave," 24th International Conference on Microwave and Millimeter Wave Technology Proceedings,2004.

[11] J.-S. Hong and M. J. Lancaster, "Theory and experiment of novel microstrip slow-wave open-loop resonator filters," IEEE Transactions on Microwave Theory and Techniques, vol. 45, no.12, part 2, pp. 2358-2365, 1997.

[12] Hizan, H.M, et al., "Q-band millimeter-wave SIW filter using LTCC technology". 2014 IEEE Asia-Pacific Conference on Applied Electromagnetics, APACE 2014 - Proceeding, pp.199-202. 


\section{BIOGRAPHIES OF AUTHORS}

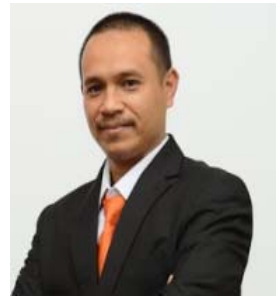

Zulkifli Ambak is a Senior Researcher at Communication Technologies Division, Telekom Malaysia Research and Development (TM R\&D). He received the B. Eng. (with Honors) in Electrical and Electronic Engineering from the Manchester Metropolitan University,UK. in 1998. Upon graduation, he joined Sharp Electronic Malaysia Sdn Bhd as an R\&D Engineer involved in R\&D for design and developed television brand SHARP for NTSC and PAL market. After 8 years at Sharp Electronic Malaysia Sdn Bhd, he decide to join TM Research and Development Sdn Bhd in Dec 2006 as Researcher until now. His research projects include Low temperature co -fired Ceramic (LTCC) technologies, microwave filters and antenna, millimeter wave transceivers system, Radio-over-fiber (RoF), LTE and WiFi technologies. Some of the projects which he has involved had been awarded the Winner of Best Broadband Partnership at Broadband Infovision Awards on Green Collaboration Optical Radio Network (G-CORN) at Amsterdam, Netherland (2014), Merit Award on Green Fiber Wireless (G-FiWi) Technology in Asia Pacific ICT (APICTA 2013), Malaysia and Merit Award on Vital Wireless Dongle (VWiD) Technology in Asia Pacific ICT (APICTA 2017), Malaysia. Currently, he is doing his PHD Industry in School of Graduate Studies at Universiti Teknologi Malaysia since 2012.

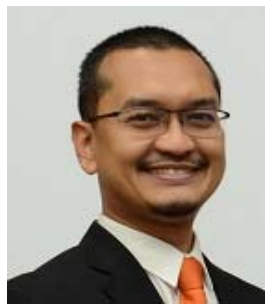

Dr. Hizamel is a Senior Researcher at Communication Technologies Division, TM Research and Development Sdn Bhd. He received the B. Eng. (with Honors) in Electronic and Communication Engineering from the University of York, U.K. in 1999, M.Sc. (with Distinction) in RF and Communication Engineering from the University of Bradford, U.K. in 2003 and Ph.D. in Electronic and Electrical Engineering from University of Leeds, U.K. in 2011. Upon graduation, he joined Telekom Malaysia as an Engineer involved in various technologies from WCDMA to WDM systems. He is an Editorial Board member of TM R\&D publication committee. His research projects include integrated microwave filters and antenna, millimeter wave transceivers system, Radio-over-fiber (RoF) and WiFi technologies. He has been a member of Industrial Advisory Board (IAB) at Centre on Optical Wireless Application (COWA), National Science Foundation at Georgia Institute of Technology, Atlanta, USA. Some of the projects which he has involved had been awarded the Winner of Best Broadband Partnership at Broadband Infovision Awards on Green Collaboration Optical Radio Network at Amsterdam, Netherland (2014) and Merit Award on Green Fiber Wireless Technology in Asia Pacific ICT (APICTA 2013), Malaysia. Dr. Hizamel is a member of IEEE (MTT/AP/EMC) and Board of Engineers Malaysia.

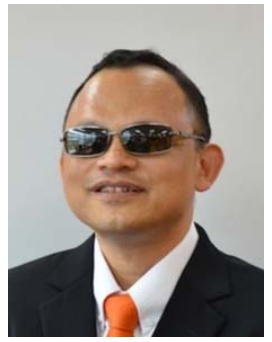

Ahmad Ismat Abdul Rahim (drismat@tmrnd.com.my) was born in Penang, Malaysia in 1971. He received his B.Eng (Hons.) in Electrical Engineering, MSc. in Microelectronics Systems Design and Ph.D in Microelectronics in 1994, 1995 and 1999 respectively, all from the University of Southampton, England, U.K. He was Technology Development Leader with MIMOS Berhad (www.mimos.my) involved in the development of 0.35um CMOS, BiCMOS and SiGe technologies; Wafer Fabrication Specialist \& TCAD Sales Engineer for IC Microsystems Sdn. Bhd. (www.icmic.com) and Senior Design Engineer, Penang Design Center, Intel Microelectronics (M) Sdn. Bhd. responsible for design-process interaction analysis and device physics-design investigation and for P1263 $(90 \mathrm{~nm})$ process model characterization for next generation chipset design. He is currently Associate Principal Researcher in the Advanced Physical Laboratory at Telekom Malaysia R\&D Sdn. Bhd. (www.tmrnd.com.my), involved in the development of MMICs and RFICs for applications in Radio-Over-Fiber (ROF) and Fiber Wireless (FiWi) systems for Gbps Next Generation Broadband communication systems. Ahmad Ismat has published over 50 technical papers and filed 4 patents. His research interests are in device and circuit design and modeling for MMICs and RFICs.

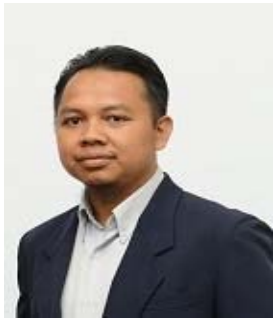

Azmi Ibrahim is a Researcher at Communication Technologies Division, TM Research and Development Sdn Bhd. He received the B.Sc. (Hons) and M.Sc in Physics from The National University of Malaysia in 2002 and 2008 respectively. His research projects include Low temperature co -fired Ceramic (LTCC) technologies, microwave filters and antenna, millimeter wave transceivers system, Radio-over-fiber (RoF), LTE and WiFi technologies. 


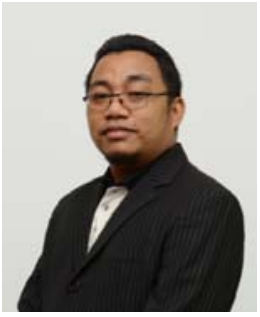

Mohd Zulfadli Mohamed Yusoff is a Researcher at Connected Mobility Unit under Communication Technologies Division, Telekom Malaysia Research and Development (TM R\&D). He received the B. Eng. (with Honors) in Mechanical and Material Engineering from the National University of Malaysia in 2004. Upon graduation, he joined Kein Hing Industri Sdn Bhd as Quality Engineer for taking responsibility the quality of a company's products. After 3 years at Kein Hing, he decide to join TM Research and Development Sdn Bhd in March 2008 as Researcher until now. His research projects include Low temperature co -fired Ceramic (LTCC) technologies, microwave filters and antenna, millimeter wave transceivers system, Radio-over-fiber (RoF), LTE and WiFi technologies. Some of the projects which he has involved had been awarded the Winner of Best Broadband Partnership at Broadband Infovision Awards on Green Collaboration Optical Radio Network (G-CORN) at Amsterdam, Netherland (2014), Merit Award on Green Fiber Wireless (G-FiWi) Technology in Asia Pacific ICT (APICTA 2013), Malaysia and Merit Award on Vital Wireless Dongle (V-WiD) Technology in Asia Pacific ICT (APICTA 2017), Malaysia.

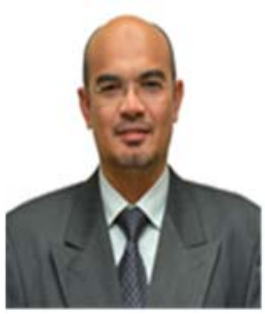

Razali Ngah received the Ph.D. degree from the University of Northumbria, United Kingdom, in 2005. Since 1989, he has been with the Faculty of Electrical Engineering, Universiti Teknologi Malaysia (UTM), where he is currently a Associate Professor. He is also the Deputy Director of Wireless Communication Centre in UTM. His research interests include antennas and propagation for communications, radio over fiber and photonic networks. 